\title{
Histomorphometric evaluation of adult male rabbit testicular tissue exposed to giant milk weed (Calotropis procera) treatment
}

\author{
Emmanuel Olusola Yawson ${ }^{1}$, Lawal Ismail Temitayo ${ }^{2}$, Kosisochukwu Kingsley Obasi ${ }^{2}$, \\ Abdulrahman Abdulfatai ${ }^{1}$, Wasiu Olalekan Akintunde ${ }^{1}$ \\ ${ }^{1}$ Department of Anatomy, Faculty of Basic Medical Sciences, College of Health Sciences, Ladoke Akintola University of Technology, Ogbomoso, Nigeria \\ ${ }^{2}$ Department of Anatomy, Faculty of Basic Medical Sciences, College of Health Sciences, University of Ilorin, Ilorin, Nigeria
}

\begin{abstract}
Objectives: This study was designed to investigate the effects of liquid extract of Calotropis procera (CP) on the testicular structure and functions of adult male rabbits. CP, commonly known as 'ewe bomubomu' in Nigeria, contains a toxic milky sap that is extremely bitter; the milky sap contains a complex mix of chemicals. This plant is most popular and commonly used among the Fulanis in Nigeria to process cheese.

Methods: Twelve adult male rabbits weighing between 1-2 kg were used for this study. The rabbits were divided randomly into four Groups A-D; ( $n=3$, in each group). Animals in Group A-C received CP as 750, 500 and 250 mg/kg body weight, respectively by oral intubation daily for 28 days, while Group D served as the control group. All animals were euthanized by cervical dislocation; the testes were excised and fixed in Bouin's fluid for routine histological studies using haematoxylin and eosin stain. Cauda epididymidis was also excised for semen quality evaluation.

Results: These results showed hormonal and testicular histomorphological alterations in CP treated animals such as abnormal shape and arrangement of seminiferous tubules, degeneration of spermatogenic and interstitial. CP also affected the testosterone concentration, cross-sectional area, germinal epithelium diameter and lumen diameter of the seminiferous tubules.

Conclusion: These findings show that CP caused histomorphological and hormonal alterations and thereby hampered spermatogenesis. It is therefore recommended that continuous use of CP as part of food ingredient should be discouraged and discontinued.
\end{abstract}

Keywords: Calotropis procera; rabbit; testes

Anatomy 2017;11(1):1-5 (02017 Turkish Society of Anatomy and Clinical Anatomy (TSACA)

\section{Introduction}

Calotropis procera (CP; giant milk weed) is a species of flowering plant in the family Apocynaceae, native to North Africa, Tropical Africa, Western Asia, South Asia, and Indochina. ${ }^{[1]}$ The flesh CP contains a toxic milky sap that is extremely bitter and turns into a gluey coating resistant to soap. ${ }^{[1]}$ The milky sap contains a complex mix of chemicals, some of which are steroidal heart poisons known as 'cardiac aglycones'. ${ }^{[2,3]}$ These belong to the same chemical family as similar chemicals found in foxgloves (digitalis purpurea). Alkaloids, flavonoids, sterols and uscharin have also been reported to be present in the entire part of the plant. ${ }^{[3]} \mathrm{CP}$ is referred to as 'ewe bomubomu' among the Yoruba populace in Nigeria where it is used as a constituent of concortions to cure certain ailments. The Fulani population in Nigeria use CP as the major component in processing cheese.

The testes are double glandular organs performing both exocrine and endocrine functions in the body. Spermatogenesis occurs in the seminiferous tubule of the testes surrounded by nutrient rich basement membrane which serves as support and source of nutrients to the pro- 
liferating spermatogenic cells to give rise to matured spermatozoa under the influence of testosterone hormone produced by cells located in the interstitial space of the testes. ${ }^{[4]}$ Spermatogenesis and testosterone production are regulated by the secretory actions of the hypothalamus where gonadotropin releasing hormone $(\mathrm{GnRH})$ is released and pituitary gland that secretes follicle stimulating hormone (FSH) and luteinizing hormone ( $\mathrm{LH})$ upon the action of $\mathrm{GnRH} .^{[4]}$

$\mathrm{CP}$ has been used in traditional medicine as purgative, anthelmintic, anticancer, as well as to treat leucoderma, ulcers, piles and disease of the spleen. ${ }^{[5]} \mathrm{CP}$ has been implicated to have an abortifacient, ${ }^{[6]}$ antifertility, ${ }^{[7]}$ uterine stimulating effect ${ }^{[8]}$ and teratogenic effects on the developing embryo. ${ }^{[9]}$

Fresh leaf extract of $\mathrm{CP}$ has growth suppressing effects on the body leading to a significant reduction in body, testicular and epididymal weights in exposed animals. Significant decrease in relative weights of accessory sex glands was reported in rat treated with $\mathrm{CP} \cdot{ }^{[10,11]} \mathrm{CP}$ administration led to deleterious effects on the testicular microstructures and accessory sex organs, resulting in desquamation of seminiferous epithelial cells, degeneration of seminiferous tubules and presence of large-sized multinucleated cells. Significant reduction in the seminiferous tubular diameter, seminal vesicle and epididymal structures were also reported. ${ }^{[10]}$

The aim of this study was to highlight the effects of CP on testicular morphology and morphometry, and also evaluate the consequent effects on semen parameters in adult male rabbits. This became a research of interest after observation of the use of $\mathrm{CP}$ by local fish farmers in Nigeria in the harvesting processes of fish from various local ponds, and also from the use of CP by Fulanis (a tribe in Nigeria ethnic groups) as a major constituent of their locally produced cheese popularly known as "wara fulani".

\section{Materials and Methods}

Twelve adult sexually active male rabbits weighing between 1-2 $\mathrm{kg}$ were used in this study. The rabbits were bred and maintained at the experimental animal unit in the Department of Human Anatomy, Ladoke Akintola University of Technology, Ogbomoso, Nigeria. The animals were divided into four groups (of three rabbits each), designated as Groups A-D. Groups A-C served as experimental animals, and Group D served as control.

The leaves of CP were obtained from Aroje community, Ogbomoso, and identified at the Department of Pure and Applied Biology, Ladoke Akintola University of Technology, Ogbomoso, Oyo State, Nigeria. The leaf extract of $\mathrm{CP}$ was prepared by macerating $50 \mathrm{~g}$ of fresh leaves with $250 \mathrm{ml}$ of distilled water and later by squeezing and filtering. The filtrate served as the stock solution. The stock solution was administered orally at a dosage of $750 \mathrm{mg} / \mathrm{kg}$ body weight (Group A), $500 \mathrm{mg} / \mathrm{kg}$ body weight (Group B), and $250 \mathrm{mg} / \mathrm{kg}$ body weight (Group C) once daily using an oral cannula for 28 days. Control animals (Group D) received only normal saline for the same number of days.

The animals were dissected, and the testes and epididymis were collected immediately after exsanguination. The testes collected were fixed in Bouin's fluid and processed using paraffin embedment, and stained with haematoxylin and eosin. The slides of testes were evaluated for pathological changes under light microscope. The testes used for hormonal assay were crushed using a pestle and mortar in a $0.25 \mathrm{M}$ sucrose solution, then centrifuged for $5 \mathrm{~min}$ at $5000 \mathrm{r} / \mathrm{min}$ and filtered using a plastic pipette. The specimens for the testosterone assay were kept in the freezer at a temperature of about $-5^{\circ} \mathrm{C}$ before the assay commenced.

The epididymis was placed in normal saline for evaluation of sperm quality (i.e. sperm count, sperm motility and sperm morphology). The concentration of spermatozoa was determined by the haemocytometer method. The spermatozoa were evaluated by haemocytometer using the improved Neubauer chamber (Deep 1/10 mm; LABART, Munich, Germany).

The histomorphometry (i.e. cross section area, lumen diameter and germinal epithelium diameter) was evaluated using Image J software (National Institute of Mental Health, Bethesda, Maryland, USA) from photomicrographs of the testes.

Johnsen score was used for assessing spermatogenesis in testicular biopsy: ${ }^{[12]} 10$ : complete spermatogenesis and perfect tubules; 9: many spermatozoa present but disorganized spermatogenesis; 8: only a few spermatozoa present; 7: no spermatozoa but many spermatids present; 6: only a few spermatids present; 5: no spermatozoa or spermatids present but many spermatocytes present; 4: only a few spermatocytes present; 3 : only spermatogonia present; 2: no germ cells present; 1: neither germ cells nor Sertoli cells present.

Testosterone concentration was estimated using Accu Bind ELISA Microwell (Monobind Inc., Lake Forest, CA, USA).

Data collected were analyzed using two-way analysis of variance (ANOVA) followed by Tukey's (HSD) multiple comparison test with the aid of SPSS (V20; SPSS 
Inc., Chicago, IL, USA). Data were presented as means \pm SEM (standard error of mean). P value less than 0.05 $(\mathrm{p} \leq 0.05)$ was considered statistically significant. All graphs were drawn using the GraphPad Prism v.6 (GraphPad Software, Inc., La Jolla, CA, USA).

\section{Results}

\section{Histological analysis}

Histological findings in the control group depicted a normal cytoarchitecture of the testes in rabbits showing a normal shape and arrangement of seminiferous tubule with intact basement membrane and progressive proliferation of spermatogenic cells to produce matured spermatozoa. Interstitium was intact with Leydig cells (Figures 1a and b). Group $\mathrm{C}$ rabbits had swollen spermatogonia and mild disruption in the arrangement of seminiferous tubule (Figures 1c and d). Group B treated rabbits showed impaired spermatogenesis due to degeneration of spermatogenic cells, necrosis of Leydig cells in the interstitium, and traces of haemorrhage were evident (Figures 1e and f). In Group A rabbits, there were reduced spermatogenic cells and impaired spermatogenesis, and traces of spermatogenic cells were secluded in the lumen (Figures $1 \mathrm{~g}$ and $\mathbf{h})$.

Group D (control) animals showed normal shape and arrangement of seminiferous tubule with intact basement membrane and progressive proliferation of spermatogenic cells to produce matured spermatozoa. There was intact interstitium with Leydig cells. The basement membrane covering of the seminiferous tubule was normal across all groups (Figures 1a and b). Group B animals showed swollen spermatogonia and mild disruption in the arrangement of seminiferous tubule (Figures 1c and d). Group C animals showed hampered spermatogenesis due to degeneration of spermatogenic cells, necrosis of Leydig cells in the interstitium and traces of haemorrhage were evident (Figures 1e and f). Group D animals reduced spermatogenic cells and hampered spermatogenesis as traces of spermatogenic cells were present in the lumen (Figures $1 \mathrm{~g}$ and $\mathbf{h})$.

Effect of CP on sperm count, motility and morphology in the epididymis of experimental group rabbits compared to the control group are shown in Table $\mathbf{1}$.

Table 1

Effect of CP on sperm parameters in the epididymis of experimental group rabbits (Groups $\mathrm{A}-\mathrm{C}$ ) compared to the control group (Group D).

\begin{tabular}{lccc}
\hline Groups & $\begin{array}{c}\text { Sperm count } \\
(\mathbf{1 0} / \mathbf{m l})\end{array}$ & $\begin{array}{c}\text { Sperm motility } \\
\mathbf{( \% )}\end{array}$ & $\begin{array}{c}\text { Sperm morphology } \\
\mathbf{( \% )}\end{array}$ \\
\hline A & $11.33 \pm 2.59^{*}$ & $46.7 \pm 12.02^{*}$ & $56.67 \pm 2.85^{*}$ \\
B & $33.07 \pm 5.64^{*}$ & $55 \pm 18.93^{*}$ & $53.33 \pm 3.84^{*}$ \\
C & $55 \pm 3.2^{*}$ & $88.73 \pm 2.02$ & $70 \pm 5.78^{*}$ \\
$D$ & $83 \pm 11.12$ & $90 \pm 0.58$ & $83.33 \pm 3.84$ \\
\hline
\end{tabular}

Values are expressed as mean \pm SEM. ${ }^{*} \mathrm{p}<0.05$
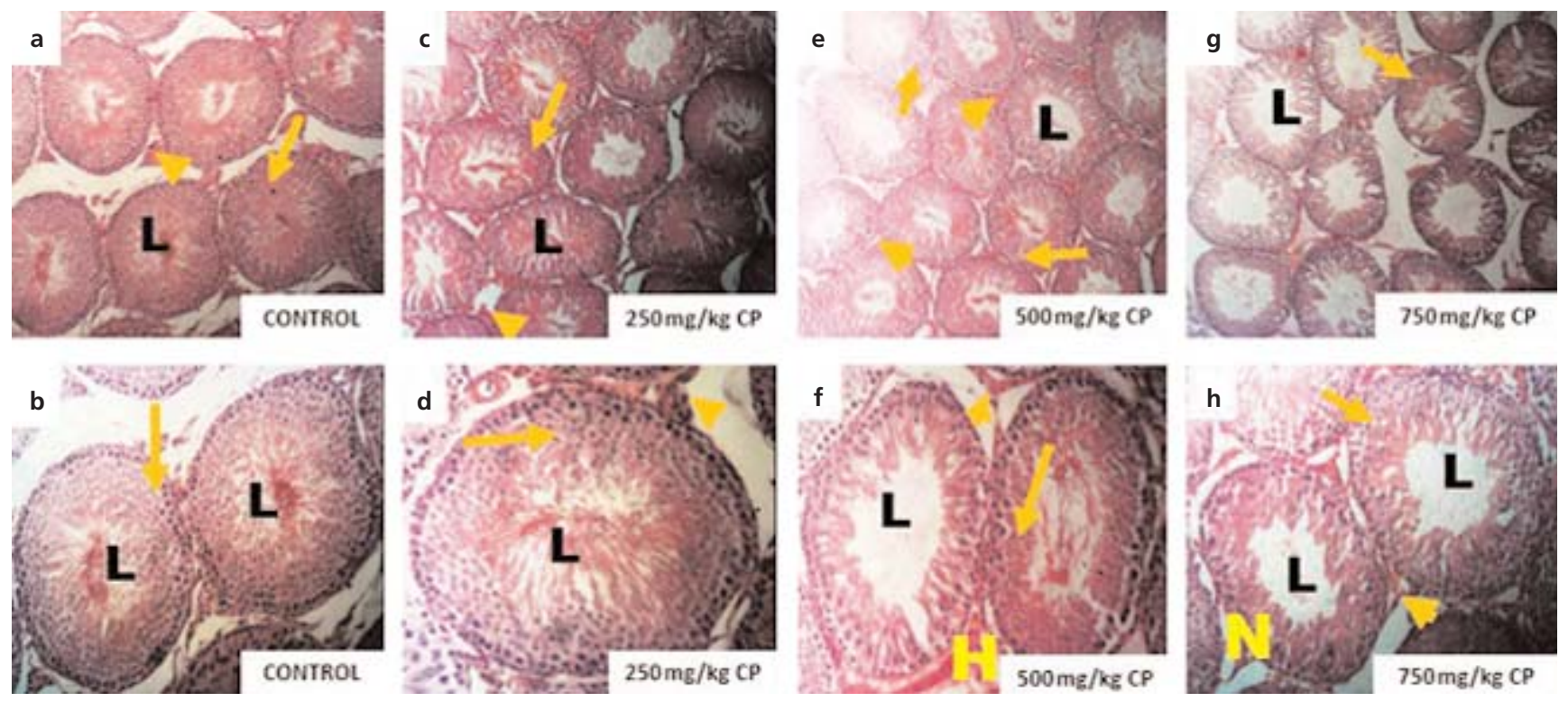

Figure 1. Photomicrographs showing rabbit testicular cytoarchitecture. Basement membrane (arrow), lumen (L), spermatogenic cells (long arrow), interstitial space (arrowhead), necrosis (N). H\&E stain, $\times 100(\mathbf{a}, \mathbf{c}, \mathbf{e}, \mathbf{g})$ and $\times 200$ (b, d, f, h). [Color figure can be viewed in the online issue, which is available at www.anatomy.org.tr] 


\section{Histomorphometric analysis and Johnsen's score}

A significant decrease $(\mathrm{p}<0.05)$ in the cross sectional area (CSA) was observed in Group C treated with $250 \mathrm{mg} / \mathrm{kg}$ body weight of $\mathrm{CP}$ when compared with the control group. A significant increase $(\mathrm{p}<0.05)$ in the germinal epithelium diameter (GED) was observed in Group A that received $750 \mathrm{mg} / \mathrm{kg}$ body weight of CP compared to the control group (Table 2), while a significant decrease $(\mathrm{p}<0.05)$ in germinal epithelium diameter was also observed in Group B that received $500 \mathrm{mg} / \mathrm{kg}$ body weight of CP compared to the control group. A significant increase $(\mathrm{p}<0.05)$ in lumen diameter was observed in Group B that received $500 \mathrm{mg} / \mathrm{kg}$ body weight of CP compared to the control group (Table 2), while a non-significant decrease $(p>0.05)$ in Johnsen's score was observed in all the treatment groups when compared to the control group (Table 2). These results showed a poor morphometric grading and poor Johnsen's score as a result of the effect of aqueous extract administration of CP.

\section{Hormonal assay}

Testosterone concentration in the testes reduced significantly $(\mathrm{P} \leq 0.05)$ in all treated groups when compared to the control group (Figure 2).

\section{Discussion}

$\mathrm{CP}$ contains toxic milky sap which is made up of complex mix of chemicals, some of which are steroidal heart poisons known as "cardiac aglycones". ${ }^{[2,3]} \mathrm{CP}$ has been reported to have numerous medicinal importance, ${ }^{[3,5]}$ but was observed to be potentially injurious to the body especially male reproductive organs after prolonged or chronic use. ${ }^{[1,10]} \mathrm{CP}$ induced functional sterility, degenerating and necrotic germ cells within the seminiferous tubule and significantly reduced testicular weight. ${ }^{[13]}$

In this present study, histopathological findings revealed that $\mathrm{CP}$ caused mild distortions on the histomorphology of animals treated with $250 \mathrm{mg} / \mathrm{kg}$ body weight. Animals given $500 \mathrm{mg} / \mathrm{kg}$ body weight of CP and $750 \mathrm{mg} / \mathrm{kg}$ body weight of CP showed mixing of the germ cell types in stages of spermatogenesis and hypertrophy of the spermatogenic cells in animals that received $750 \mathrm{mg} / \mathrm{kg}$ body weight of $\mathrm{CP}$, complemented with abnormal rise in germinal epithelium diameter, reduced spermatozoa and presence of spermatogenic cells in the lumen. The seminiferous tubules showed abnormal shape (shrinkage) and arrangement (wide interstitial space). This finding was further complimented by reduction in the cross section area of the seminiferous tubules. Wide interstitium with degenerated testosterone producing Leydig cells and traces of haem-
Table 2

Effect of CP on histomorphometric parameters and (Jonhsen's score) in experimental group rabbits (Groups $A-C$ ), compared to the control group (Group D).

\begin{tabular}{lcccc}
\hline Groups & $\begin{array}{c}\text { CSA } \\
(\mathbf{1 0 7} \boldsymbol{\mu m})\end{array}$ & $\begin{array}{c}\text { GED } \\
(\mathbf{1 0} \boldsymbol{\mu m})\end{array}$ & $\begin{array}{c}\text { LD } \\
(\mathbf{1 0 2} \boldsymbol{\mu m})\end{array}$ & $\begin{array}{c}\text { Johnsen's } \\
\text { score }\end{array}$ \\
\hline A & $2.8 \pm 0.42$ & $1.18 \pm 0.05^{*}$ & $7.7 \pm 0.66$ & $5.7 \pm 0.33$ \\
B & $2.5 \pm 0.29$ & $0.69 \pm 0.12^{*}$ & $17.1 \pm 10.5^{*}$ & $5.7 \pm 0.33$ \\
C & $1.5 \pm 0.13^{*}$ & $0.94 \pm 0.05$ & $8.05 \pm 0.31$ & $6.0 \pm 0.58$ \\
D & $2.6 \pm 0.26$ & $0.89 \pm 0.06$ & $9.70 \pm 0.79$ & $7.0 \pm 0.58$ \\
\hline
\end{tabular}

CSA: cross sectional area, GED: germinal epithelium diameter, LD: lumen diameter. Values are expressed as mean \pm SEM. ${ }^{*} p<0.05$

orrhage were also observed. These findings are consistent with the study of Sharma and $\mathrm{Jacob}^{[14]}$ who reported that CP had anti-spermatogenic properties.

Semen quality evaluation revealed dose-dependent decrease in the semen parameters. Animals treated with CP showed significant reduction in total number of sperm cells, motility and normal morphology with increasing dosage of administered $\mathrm{CP}$ as most reduction in the semen parameters were observed in animals given $750 \mathrm{mg} / \mathrm{kg}$ body weight of CP for 28 days. Histomorphological alterations and reduced semen quality observed were complimented by Johnsen's spermatogenesis score. Spermatogenesis rate and population of spermatogenesis series were insignificantly reduced in $\mathrm{CP}$ treated animals with increasing dosage.

Testosterone concentration in the testes of CP treated animals reduced $(\mathrm{p}<0.05)$ markedly compared to control group. Testosterone drives the progression of spermatogenic series in the seminiferous tubule. Reduced testosterone implies hampered rate of sperm production. Reduction in testosterone concentration and alteration

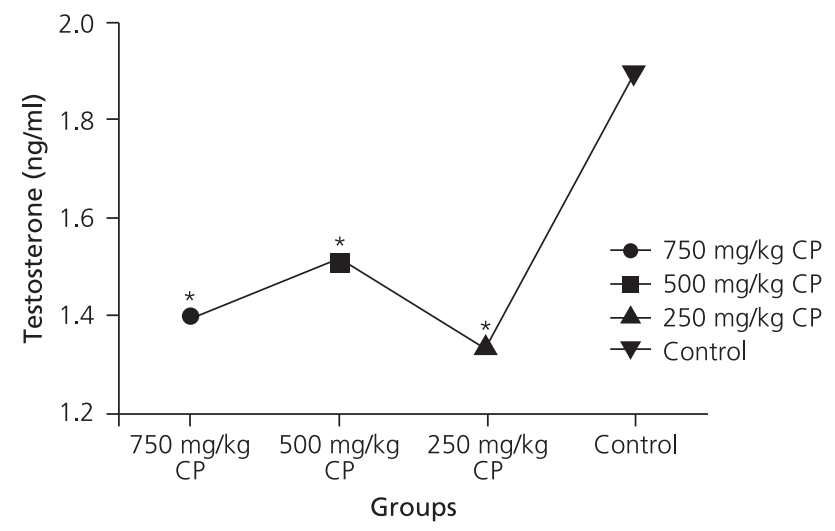

Figure 2. Testosterone concentration in control and CP-treated groups. ${ }^{*} \mathrm{p} \leq 0.05$. 
in spermatogenesis were observed in CP treated rabbits. This finding corroborated with studies by Aiton ${ }^{[1]}$ who suggested that CP had an effect on testosterone production, thereby resulting in the histomorphological alterations observed in their work.

\section{Conclusion}

Histomorphological and hormonal alterations in CP treated animals were observed such as abnormal shapes and arrangement of seminiferous tubules, degeneration of spermatogenic and interstitial cells; thereby hampering spermatogenesis. CP also affected testosterone concentration and cross sectional area, germinal epithelium diameter and lumen diameter of the seminiferous tubules in adult male rabbits. Findings from this study conducted on male rabbits showed that $\mathrm{CP}$ may be one of the underlying cause of male infertility in Nigeria as a result of daily consumption of $\mathrm{CP}$ from the popular locally made Fulani cheese, corroborating several studies carried out on different animal species. It is therefore recommended that continuous use of $\mathrm{CP}$ as a food ingredient should be discouraged and discontinued as CP, causes testicular toxicity on dose dependent levels.

\section{Acknowledgements}

We would like to acknowledge KK Obasi, IA Lawal, AO Abdulrahman, and OW Akintunde for their technical assistance.

\section{References}

1. Aiton WT. Calotropis procera: Germplasm resources information network. United States Department of Agriculture; 2001-10-19. Retrieved 2010- 06-26.

2. Al-Robal AA, Abo-Khatwa AN, Danish EY. Toxocological studies on the latex of the usher plants Calotropis procera (ait). R. Br. In Saudi
Arabia 111. Effects of usher latex on the fine structures, oxygen consumption and $\mathrm{Na}+\mathrm{k}+$ transporting ATPase activity of albino rat kidneys. Arab-Gulf Journal of Scientific Research 1993;11:441-5.

3. Hussein HI, Kamel A, Abou-Zeid M, Abdel-Khalek, El-Sebae H, Saleh MA. Uscharin, the most potent molluscicidal compound tested against land snails. J Chem Ecol 1994;20:135-40.

4. Scott FG. Developmental biology online textbook. 6th ed. Sunderland (MA): Sinauer Associates Inc; 2000. p. 21.

5. Jain SC, Sharma R, Kain R, Sharma RA. Antimicrobial activity of Calotropis procera. Fitoterapia 1996;67275-7.

6. Saha JC, Savini EC, Kasinathan S. Ecbolic properties of Indian medicinal plants. Part 1. Indian Journal of Medical Reources 1961; 49:130-51

7. Malhi BS, Trivedi VP. Vegetable antifertility drugs of India. Q J Crude Drug Res 1972;12:1922.

8. Hilai SH, Youngken JR. Certain poisonous plants of Egypt. A scientific manual pharmaceutical society of Egypt. National Information and Documentation; Centres Dokki, Cairo, Egypt: 1983. p. 11.

9. Prakash AO, Gupta RB, Mathur R. Effect of oral administration of forth two indigenous plant extracts on early and late pregnancy in albino rats. Probe 1978;17:315-23.

10. Akinloye AK, Abatan MO, Onwuka SK, Oke BO. Growth-suppressing effect of Calotropis procera (giant milkweed) on body weight and the male reproductive organs of wistar rats. Tropical Animal Health and Production 2002;20:132-8.

11. Akinloye AK, Abatan MO, Alaka OO. Histomorphometric and histopathological studies on the effect of Calotropis procera (giant milkweed) on the male reproductive organs of Wistar rats. International African Journal of Biomedical Research 2002;5:57-61.

12. Johnsen SG. Testicular biopsy score count - a method for registration of spermatogenesis in human testes: normal values and results in 335 hypogo- nadal males. Hormones 1970;1:2-25.

13. Meerwal P, Jain GC. Male fertility regulation with plant products: a review. International Journal of Pharmaceutical, Chemical and Biological Sciences 2015;5:146-62.

14. Sharma N, Jacob D. Inhibition of fertility and functional alteration in the genital organs of male Swiss albino mouse after administration of Calotropis procera flower extract. Pharmaceutical Biology 2001;39: 403-7.

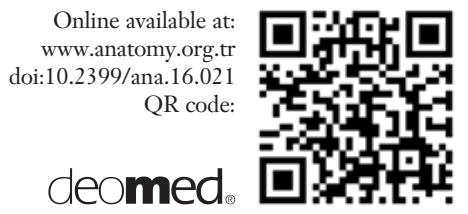

Correspondence to: Emmanuel O. Yawson, MSc, PhD Department of Anatomy, Faculty of Basic Medical Sciences, College of Health Sciences, Ladoke Akintola University of Technology, Ogbomoso, Nigeria Phone: +2348136725089

e-mail: yawsonmmanuel@gmail.com

Conflict of interest statement: No conflicts declared.

This is an open access article distributed under the terms of the Creative Commons Attribution-NonCommercial-NoDerivs 3.0 Unported (CC BY-NCND3.0) Licence (http://creativecommons.org/licenses/by-nc-nd/3.0/) which permits unrestricted noncommercial use, distribution, and reproduction in any medium, provided the original work is properly cited. Please cite this article as: Yawson EO, Temitayo LI, Obasi KK, Abdulfatai A, Akintunde WO. Histomorphometric evaluation of adult male rabbit testicular tissue exposed to giant milk weed (Calotropis procera) treatment. Anatomy 2017;11(1):1-5. 